\title{
Exchange Rate Transaction of International Trade Goods Based on Fuzzy Granulation and Deep Learning
}

\author{
Jin $\mathrm{Hu}^{1}$ and Li Han ${ }^{2}$ \\ ${ }^{1}$ International Business School, Shandong Vocational and Technical University of International Studies, Rizhao, \\ Shandong 276826, China \\ ${ }^{2}$ School of Management, Qufu Normal University, Rizhao, Shandong 276826, China \\ Correspondence should be addressed to Li Han; hanli@qfnu.edu.cn
}

Received 8 October 2021; Revised 25 October 2021; Accepted 23 November 2021; Published 21 December 2021

Academic Editor: M. Pallikonda Rajasekaran

Copyright (c) 2021 Jin Hu and Li Han. This is an open access article distributed under the Creative Commons Attribution License, which permits unrestricted use, distribution, and reproduction in any medium, provided the original work is properly cited.

The change of international trade goods exchange rate transaction has an impact on economic operations and economic stability. Therefore, an international trade goods exchange rate transaction based on fuzzy granulation and in-depth learning is proposed. Based on fuzzy information granulation and BP neural network, this paper analyzes the interest rate evaluation theory. For the future expectation of currency exchange rate, portfolio equilibrium determines the proportional relationship of each component in the portfolio and analyzes the impact of asset price and exchange rate change according to this relationship. Then, it points out the risk evaluation index system, calculates the risk degree of exchange rate transaction of international trade goods, and then evaluates the risk of exchange rate transaction of international trade goods. It completes the research on exchange rate transactions of international trade goods based on fuzzy granulation and in-depth learning. The experimental results show that excessive exchange rate fluctuation will bring the same proportion fluctuation to the asset price in the financial market, and the coordination between exchange rates and the coordination of exchange rate and asset price can promote the steady growth of national economy.

\section{Introduction}

Exchange rate, also known as foreign exchange rate, is the conversion ratio between one currency and another, usually in the form of currency pairs $[1,2]$. With the rapid development of economic globalization, international trade has entered and affected all aspects of life [3]. As the yardstick of international trade settlement, exchange rate, as the standard of settlement in international trade, plays an important role in adjusting the economic lever. The change of exchange rate is closely related to many factors, such as economy, politics, and culture. On the one hand, it is comprehensively affected by many factors. On the other hand, the fluctuation of the exchange rate will directly affect the direction of import and export trade and then affect macroeconomics, politics, and culture $[4,5]$. There are generally two types of practitioners participating in the foreign exchange market: first, foreign traders, practitioners of commodity trade of transnational entities [6], who exchange currencies or commodity entities according to exchange rates and, second, professional speculators, who are specialized in foreign exchange futures market transactions, and there is no exchange of commodities or currencies. More and more attention has been paid to the exchange rate transactions of related international trade goods.

Taking the transaction level evidence of Pakistan as an example, the study in [7] puts forward the impact of the exchange rate on agricultural exports, including the response of price and quantity differences. Highly classified company-level data has been used, including the exchange rate of the actual currency of the transaction level invoice. It is found that currency depreciation has a positive impact on both intensive and extensive profit margins. The intensive growth of the export profit margin of agricultural products is mainly realized through price, while the response of quantity is relatively small. In addition, depreciation improves the broad profits of enterprises and products and expands the customer base of the existing market. These reactions vary 
greatly due to the company's export experience, trade orientation, sectoral and spatial distribution, exchange rate system, and invoice currency. The study in [8] proposed dynamic pricing and exchange rate transmission (evidence from transaction-level data). Enterprises pricing flexibly considers the current market conditions and other factors. It provides a theoretical model to illustrate how foreign producers and domestic retailers adjust prices according to exchange rate fluctuations for three forms of dynamic pricing. Although the above research has made some progress, in today's economic globalization, the exchange rate is related to the circulation of goods all over the world, and exchange rate transaction is an important research topic. There are many reasons for the change of exchange rate transactions in the market. Therefore, an exchange rate transaction of international trade goods based on fuzzy granulation and deep learning is proposed. Fuzzy information granulation and deep learning are the results of whether the prediction of exchange rate fluctuation range is profitable. By combining fuzzy granulation and deep reliability network, the prediction of exchange rate fluctuation range is proposed.

\section{Methods}

2.1. Fuzzy Information Granulation. The concept of information granulation exists in many different fields. Different levels of granularity have different information expressions. Generally, the ordered granularity can get more information than the sorted granularity. Information grain is the process of data abstraction and the information entity of information knowledge derivation. The purpose of information granulation is to simplify complex problems so that some redundant and irrelevant information can be eliminated. The methods of information granulation include interval calculation, rough set, and fuzzy set. These methods can be summarized as discrete information granulation and fuzzy information granulation.

How to use fuzzy set theory to express information granularity depends on the actual situation, which is a problem-driven situation. We give an example to illustrate the information granulation of fuzzy set theory. Figure 1 shows the height of 10 people. We need to distinguish who is tall, who is short, and who is medium. The original data is not arranged in order and looks chaotic. It is difficult for us to see some information at a glance. But it is different after ranking. We can easily know some information, such as the span of height and the height of the shortest. In this example, the purpose of information granulation is to granulate "high," "medium," and "low" from the 10 original datasets. The discrete information granulation method in Figure 2 is that $1.55,1.61$, and 1.64 are classified as "short," $1.66,1.71$, $1.76,1.78$, and 1.83 are classified as "medium," and 1.85 and 1.89 are called "high." Obviously, it is somewhat unreasonable for 1.64 to be "short" and 1.66 to be "medium." For example, $1.83,1.66,1.71,1.76$, and 1.78 are "medium."

It is almost the same height, but it is divided into two different granulation models, which are different in fuzzy information granulation. Looking at the granulation member function, the value of 1.66 people in the granularity "low" is greater than that in the granularity "medium," and 1.83 people are considered "high" by the member function, which is much more reasonable than discrete information granulation.

2.2. BP Neural Network. Error backpropagation neural network is a multilayer forward neural network for training algorithm. At present, it is one of the most widely used and developed neural networks. BP neural network consists of three or more layers of network structure, which mainly include input layer, hidden layer, and output layer. The structure of the BP neural network with three layers is shown in Figure 3.

As can be seen from Figure 3, in the BP neural network structure, the forward propagation input layer of the signal receives the input of the neural network and transmits the signal to the hidden layer, which processes the signal and then transmits it to the output layer. BP neural network has two remarkable characteristics: first, the forward propagation of signal and, second, the backpropagation of error. Among them, error backpropagation learning is an important learning mechanism of feedforward neural networks. Its learning algorithm is to correct the error and update the weights of the network step by step by way of error backpropagation. Combined with the forward propagation of the signal, the expected function mapping is gradually approximated.

Assuming that the input vector is $X=\left(x_{1}, x_{2}, x_{3}, \ldots x_{n}\right)$, the input $u_{j}$ and output $h_{j}$ of each neuron in the hidden layer are calculated by formulas (1) and (2). Finally, the output layer outputs the result of information processing. The input $l_{k}$ and output $c_{k}$ of each neuron in the output layer are calculated by formulas (3) and (4). During the signal forward propagation process, the weight of the network remains unchanged. Consider the following:

$$
\begin{aligned}
& u_{j}=\sum_{i=1}^{n} w_{i j} x_{i}+\theta_{j}, \\
& h_{j}=f\left(u_{j}\right)=\frac{1}{1+\exp \left(-u_{j}\right)}, \\
& l_{k}=\sum_{j=1}^{q} v_{j k} h_{j}+r_{k}, \\
& c_{k}=f\left(l_{k}\right)=\frac{1}{1+\exp \left(-l_{k}\right)} .
\end{aligned}
$$

2.3. Interest Rate Parity. The research scope of interest rate parity has expanded from commodity market to capital market. The main research object is the relationship between the expected exchange rate and the stock price of listed companies $[9,10]$. Interest rate parity theory reveals the intrinsic relationship between interest rate as asset price and 
$1.71,1.66,1.64,1.78,1.89$

$1.61,1.76,1.55,1.85,1.83$.
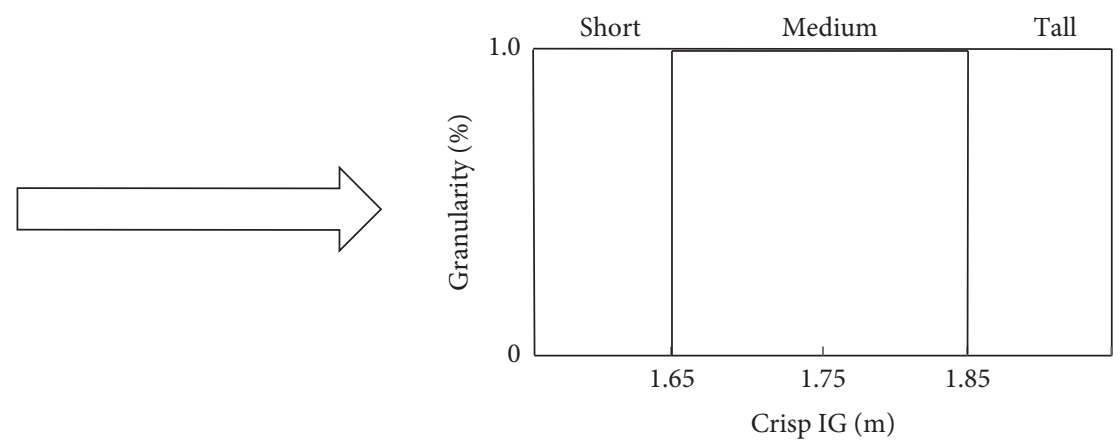

Figure 1: Discrete information granulation model.

$1.55,1.61,1.64,1.66,1.71$

$1.76,1.78,1.8 .1 .85,1.89$.
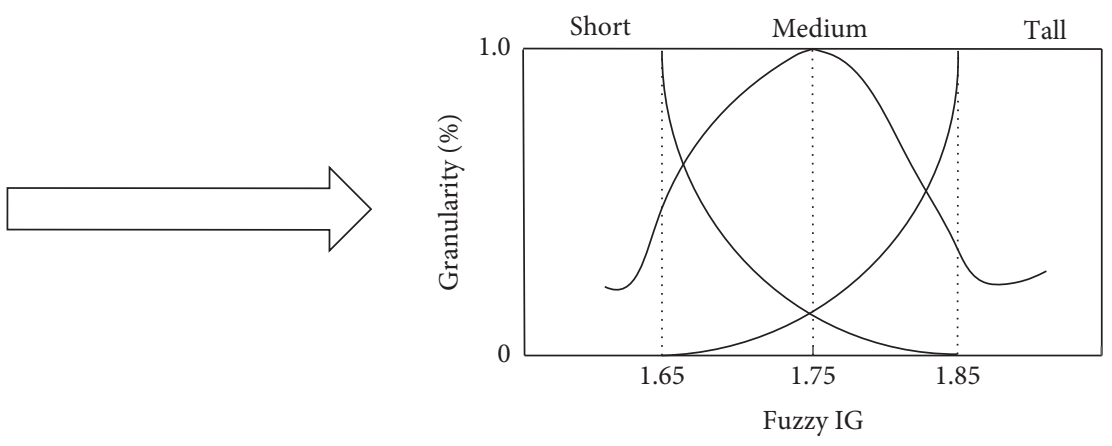

FIgURE 2: Fuzzy information granulation model.

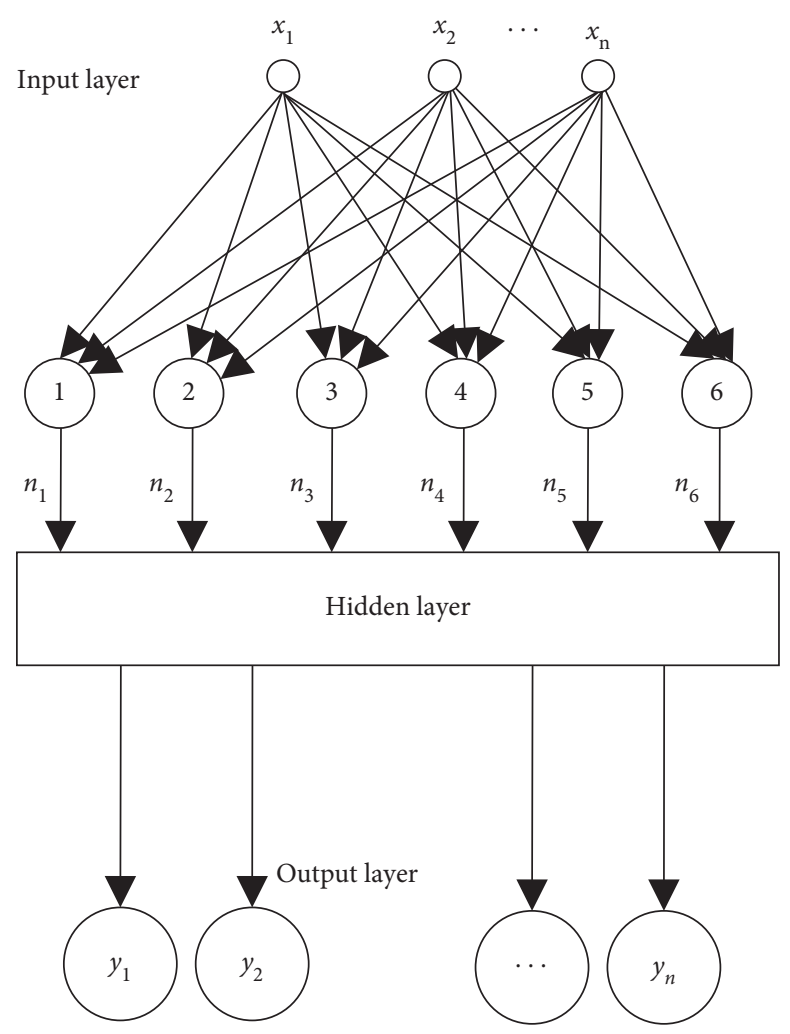

FIGURE 3: BP neural network structure diagram. 
currency exchange rate. The equilibrium parity relationship between the two can be expressed as

$$
r_{1}=r_{2}+\xi
$$

In formula (5), $r_{1}$ and $r_{2}$, respectively, represent the market interest rate level of the target country and the foreign market interest rate level, and $\xi$ is the expected appreciation rate of the exchange rate in the future. To make the algorithm more concise, stock price $p$ is used to replace asset price, and the relationship between stock price and interest rate is expressed as

$$
p=\frac{d}{\left(r_{2}+\xi+r_{0}-g\right)} .
$$

In formula (6), there is a significant negative correlation between the two variables. When the asset price $p$ rises, $\xi$ shows a downward trend, which indicates that the expectation of domestic exchange rate changes in the same proportion as the expectation of asset price. According to the above conclusion, it is concluded that the coordination effect of RMB interest rate on asset price, that is, if the expected rise of domestic currency exchange rate in the future period will lead to the rise of asset price.

As the core link of classical economic theory, the interest rate parity theory has laid the foundation of the relationship between modern finance and economy. Interest rate parity theory holds that the price level between countries will determine the level of exchange rate and reflect the purchasing power of domestic currency, while the nominal exchange rate changes around the change of real exchange rate. In the early twentieth century, the relevant research theoretical framework of asset price and currency exchange rate began to form. Experts and scholars in economics and finance all over the world begin to study the changes in interest rate and currency exchange rate from the perspective of the global foreign exchange market, stock market, and bond market. With the improvement of international trade tightness of countries all over the world $[9,11,12]$ and as the world economy becomes more integrated, financial capital flows from countries with low interest rates to countries with high interest rates, due to differences in interest rates in their domestic markets, which shows that in the process of international trade and transnational investment $[13,14]$. The fluctuation of exchange rate level actually reveals the difference in domestic interest rate levels between trading countries. Therefore, the fluctuation range and trend of RMB interest rate level reflect the development of the national macroeconomy.

2.4. Portfolio Balance. The focus of portfolio equilibrium theory is the future expectation of currency exchange rate, which can determine the proportional relationship of each component in the portfolio. According to the theory of portfolio equilibrium, there are differences in economic development models and leading industries, as well as different legal systems and tax environments. Therefore, the currency in circulation in various countries does not have a complete substitution relationship. When the proportion of the main structure of investment changes, or the price level of each asset item changes, it will indirectly affect the change of currency exchange rate, if the total wealth owned by multinational investors is further divided as follows:

$$
T=\kappa+S_{1}+S_{2}
$$

In formula (7), $\kappa$ is the total wealth owned by the investor in the country, $S_{1}$ and $S_{2}$ are the total shares of all users of the investor at home and abroad, respectively. In order to maximize the income, the investor will adjust the proportion of its asset portfolio according to the principle of the highest interest rate:

$$
\begin{aligned}
T= & \kappa\left(i, i^{*}+\Delta R, R, R^{*}\right) T+S_{1}\left(i, i^{*}+\Delta R, R, R^{*}\right) T \\
& +S_{2}\left(i, i^{*}+\Delta R, R, R^{*}\right) T .
\end{aligned}
$$

In formula (8), $i$ is the return on assets in domestic currency, $i^{*}+\Delta R$ is the expected return on foreign assets, $R$ and $R^{*}$ are the respective risks of investors holding domestic currency assets and foreign currency assets, respectively, and $\kappa\left(i, i^{*}+\Delta R, R, R^{*}\right), S_{1}\left(i, i^{*}+\Delta R, R, R^{*}\right)$, and $S_{2}\left(i, i^{*}+\Delta R, R, R^{*}\right)$ are the proportions of three assets held respectively. It can be analyzed from formula (4) that when other factors are determined and remain unchanged, if the expected exchange rate level increases, investors will increase the holding proportion of this part of assets in order to obtain greater income. This change trend shows that the expectation of interest rate level will determine the choice of investors' asset price and asset portfolio. Therefore, in international trade or transnational investment $[15,16]$, investment return and risk factors are the first consideration of capital holders, and the exchange rate will not fluctuate greatly in the short term, which is the secondary consideration of investors. Therefore, when the proportion of investors' asset portfolio changes, it will lead to changes in the money supply between the home country and the investing country, which in turn affects the changes in the currency exchange rates of both trading countries.

2.5. Impact of Changes in Asset Prices and Exchange Rates. In view of the immaturity of the capital market and the floating exchange rate system, this paper studies the relationship among asset price, exchange rate, and economic stability from the perspective of macrocapital and total labor demand, to determine its role in stable economic growth. To ensure the smooth transition of the economic development in the period of social transformation, we should implement more strict capital control policies. It is necessary to set up a multicycle macroeconomic model to study the stable relationship between finance and economy from a macroperspective. The specific steps are as follows.

Step 1. Based on the viewpoints discussed by fuzzy granulation and deep learning, the national income model $Y$ is established under the four-sector macroeconomic model, and the formula can be expressed as 


$$
Y=C+I+G+(X-M) .
$$

In formula (9), $C, I, G$, and $(X-M)$ are the total consumption, total investment, government expenditure, and net export, respectively. In the formula, residents' consumption $C$ is a function of asset price, exchange rate, and residents' disposable net income, expressed as

$$
C=g(p, \xi(Y-t))
$$

In formula (10), $g(x)$ is the consumption function and $t$ is the tax to be borne by residents. From the relationship between consumption function, it can be analyzed that the increase of exchange rate level and asset price will lead to the growth of consumption demand (the asset price referred to in this paper is the average value of real estate price and stock market price). From the perspective of investment, the total investment $I$ also has a functional relationship with domestic interest rate $r_{1}$, exchange rate $\xi$, and asset price $p$ :

$$
I=f\left(r_{1}, p, \xi\right) \text {. }
$$

Step 2. When asset prices and exchange rates continue to rise, this will stimulate an increase in domestic investment. In the process of determining the overall national income $Y$, the balance of payments account $B P$ is also one of the important influencing factors. The balance of payments account of a country consists of capital account $C_{A}$ and current account $K_{A}$. Among them, the balance of the capital account is affected by the balance of domestic and foreign interest rates $r_{1}-r_{2}$, the expected appreciation rate of assets $\gamma$, and the domestic market return $i$. At this time, the balance of payments account is

$$
B P=C_{A}\left(Y, Y^{*}, \xi\right)+K_{A}\left(\left(r_{1}-r_{2}\right), \gamma, i\right) .
$$

The variable relationship in the balance of payments account shows that the rise of asset prices can increase residents' consumption level, thus driving the improvement of exchange rate level and enterprise investment.

Step 3. Based on the original IS $=\mathrm{LM}$ model, this paper introduces the $B P$ curve of the balance of payments account, analyzes the change relationship of the three curves, and further expounds the internal relationship between asset price and exchange rate change. To analyze the overall trend of curve change more accurately, a two-phase economic system is set. It is assumed that the economic system is in a relatively balanced state at the beginning of the first phase, as shown in Figure 4.

If the exchange rate continues to rise, it will attract more overseas capital flows. At this time, the $B P$ curve will move $B P$ I to the right, and the rise of the exchange rate will also cause $I S$ and $L M$ to move to the right at the same time. When the exchange rate continues to rise abnormally, the government will adopt appropriate monetary policy and finance to maintain the stability of the domestic interest rate. Therefore, in the change of the first phase function curve, the domestic interest rate is always stable at $r_{0}$ level and will not change. At this time, the three function curves move from

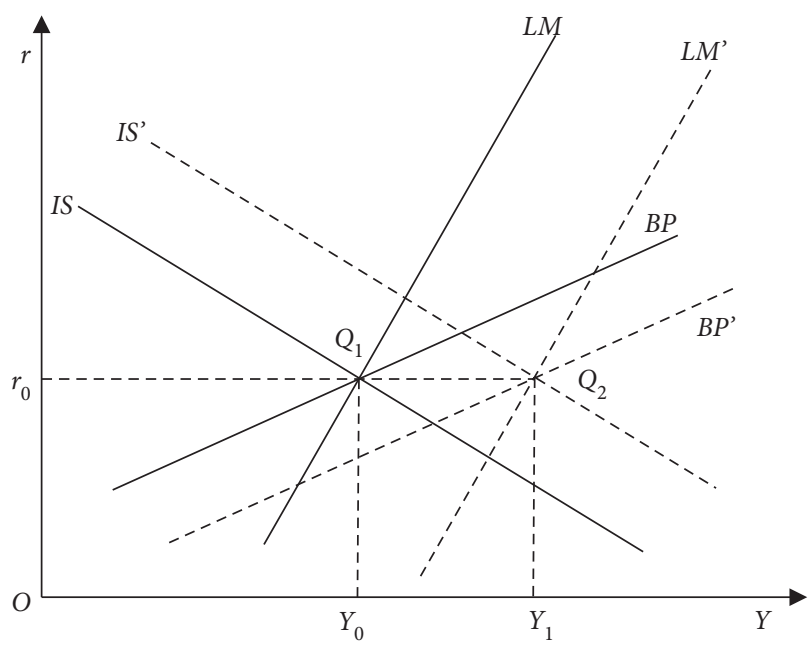

FIgURE 4: Variation relationship of each function curve in the first phase.

the initial state to the right of the equilibrium point $Q_{1}$ to the equilibrium point $Q_{2}$; that is, under the condition of constant domestic interest rate, the overall national income increases by $Y_{1}$ from $Y_{0}$. The trend of the first phase of the financial-economic model shows that when the exchange rate shows an upward trend, the domestic money supply will increase substantially due to the profitability of capital. Under the control of relevant national macrocontrol, the domestic interest rate $r_{0}$ will remain constant, so the domestic asset price will increase rapidly.

Step 4. The continuous rise of asset prices has brought more serious inflationary pressure to China, and the government authorities will take certain measures to curb the phenomenon of continuous inflation. At this time, the new changes of the three groups of curves are shown in Figure 5.

Since the balance of payments will not fluctuate violently in the short term, the curve will move to the upper left after the government takes macrocontrol measures. At the same time, the rise of exchange rate level will stimulate residents' consumption, so ISI moves to the left and down to IS 1 . From the perspective of total money supply, even if the government takes corresponding measures, it cannot fundamentally change the fact of money increase. Therefore, $L M$ ' will move to $L M \prime \prime$ accordingly, and the three curves intersect at the new equilibrium point $Q_{3}$. Under the new equilibrium conditions of the second phase, national income for the first period from $Y_{1}$ to $Y_{0}$, while domestic interest rate changes from $r_{0}$ to $r_{1}$, the increase in interest rate level will curb investors' enthusiasm for investment, cause a large amount of funds to flow to the capital market, and lead to the rise of asset prices.

To sum up, a rise in the exchange rate can lead to an increase in asset prices when they deviate too much from their intrinsic value; with the intervention of national monetary policy and investors' prediction of risk, some capital will withdraw from the domestic market. At this time, the exchange rate begins to decrease step by step to the original equilibrium point and the real state. Both the RMB 


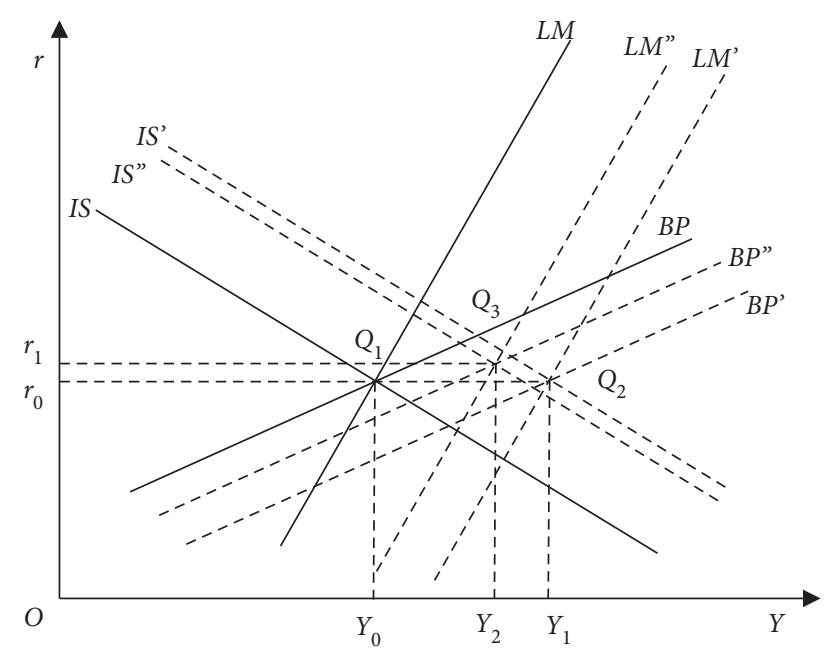

FIGURE 5: Variation trend of each function curve in secondary period.

base exchange rate and the asset price will fluctuate periodically around their real value; that is, the rise or fall of the exchange rate will lead to the change of asset price in the same direction. However, if the RMB base exchange rate increases or decreases too much in the short term, it will have an adverse impact on China's financial market and macroeconomic operation [17-19]. At the same time, as one of the important economies in the world, the excessive fluctuation of China's exchange rate also increases the unstable factors of the regional economy and has a negative impact on the development of the world economy.

\section{Exchange Rate Transaction of International Trade Goods Based on Fuzzy Granulation and Deep Learning}

3.1. Risk Assessment Index System. Based on fuzzy granulation and deep learning, this paper evaluates and estimates the exchange rate transaction risk of international trade goods through qualitative or quantitative methods.

The international trade goods exchange rate transaction risk evaluation index system is to establish relevant indicators to evaluate the international trade goods exchange rate transaction risk according to the requirements of evaluation contents and evaluation objectives [20-22]. Following the principle of risk assessment index system, the risk assessment index of international trade goods exchange rate transaction is embodied in a hierarchical model [23, 24]. The exchange rate transaction risk index system of international trade goods consists of index layer, criterion layer, and target layer, as shown in Table 1.

3.2. Calculation of Exchange Rate Transaction Risk of Goods in International Trade. There is an objective risk in the exchange rate transactions of international trade goods. Therefore, to reduce the loss caused by the objective risk, it is necessary to consider the degree of risk exposure in the exchange rate transactions of international trade goods
TABLE 1: International trade goods exchange rate transaction risk index system.

\begin{tabular}{lcc}
\hline Target layer & $\begin{array}{c}\text { Criterion } \\
\text { layer }\end{array}$ & Index layer \\
\hline & User $\alpha_{1}$ & $\begin{array}{c}\text { Seller's reputation } \alpha_{11} \\
\text { Buyer's reputation } \alpha_{12} \\
\text { Number of transactions } \alpha_{13} \\
\text { Security } \alpha_{21}\end{array}$ \\
& & Communication mode $\alpha_{22}$ \\
Transaction risk & Platform $\alpha_{2}$ & Comprehensive information \\
$\alpha$ & & $\alpha_{23}$ \\
& & Privacy protection $\alpha_{24}$ \\
& & Commodity category $\alpha_{31}$ \\
& & Transaction amount $\alpha_{32}$ \\
& Transaction $\alpha_{3}$ & Logistics quality $\alpha_{33}$ \\
& & Safeguard measures $\alpha_{34}$ \\
\hline
\end{tabular}

$[25,26]$. The risks involved in the exchange rate transactions of goods in international trade are difficult to control and will increase. The risk degree of exchange rate transaction of goods in international trade is calculated according to the transaction amount, transaction quantity, risk factor $\mu$, and transaction failure value [27-29].

The formula for calculating the risk degree of exchange rate transactions of international trade goods is as follows:

$$
V_{i j}=\mu \times f(m, n, k) .
$$

In formula (13), $0<V_{i j}<1 \circ, m$ represents the amount of exchange rate transactions of goods in international trade, $n$ represents the quantity of exchange rate transactions of goods in international trade $[30,31], k$ represents the failure value of the transaction [32], and $V_{i j}$ represents the risk of the transaction. Consider the following:

$$
\begin{aligned}
f(m, n, k) & =1-(1-f(m))^{(n, k)}, \\
(n, k) & =n^{\sqrt{k+1}}, \\
f(m) & =e^{-1 / m} .
\end{aligned}
$$

Formula (17) can be obtained from formulas (14)-(16). Consider

$$
V_{i j}=\mu-\mu\left(1-e^{-1 / m}\right)^{n^{\sqrt{k+1}}} .
$$

In formula (17) $0<V_{i j}<1$; the risk degree of international trade goods exchange rate transaction increases with the increase of $V_{i j}$. When $V_{i j}$ is closest to 1 , the risk degree in international trade goods exchange rate transaction is the largest, and when $V_{i j}$ is closest to 0 , the risk degree in international trade goods exchange rate transaction is the smallest. The risk factor $\mu$ is directly proportional to $V_{i j}$. When $\mu$ is larger, $V_{i j}$ is larger. The function $f(m, n, k)$ represents the amount of international trade goods exchange rate transactions and the number of international trade goods exchange rate transactions [33]. When the amount of international trade goods exchange rate transactions is greater and the number of international trade goods 
exchange rate transactions is greater, the greater the value of function $f(m, n, k)$ and the greater the risk in international trade goods exchange rate transactions.

3.3. Risk Assessment of Exchange Rate Transactions of Goods in International Trade. Through the international trade goods exchange rate transaction risk assessment trust cloud, the evaluation vector of the international trade goods exchange rate transaction risk is obtained. The evaluation trust is judged according to the time attenuation factor and factor weight, and the weighted percentage of international trade goods exchange rate transaction risk assessment is obtained through the trust evaluation value. The specific algorithm steps are as follows.

Let $U=\left\{\left(X_{1}, X_{2}, \ldots, X_{m}\right)\right\}$ be the quantitative domain of risk assessment of exchange rate transactions of goods in international trade represented by accurate figures. In the formula, $X_{1}, X_{2}, \ldots, X_{m}$ represents the attribute factors of the exchange rate trust evaluation of international trade goods, $U$ represents the exchange rate trading space of international trade goods, and $T$ represents the qualitative concept of $U$ in the exchange rate trading space of international trade goods [34, 35]. Trust cloud is the distribution $\mu\left(X_{i}\right)$ of qualitative concept $T$ mapping from international trade goods exchange rate transaction space $U$ to number domain international trade transaction space $[0,1]$. If there is a stable random distribution $\mu\left(X_{i}\right) \in[0,1]$ for any quantitative $X_{i}$, that is, $U \longrightarrow[0,1], \forall X_{i} \in U$, $X_{i} \longrightarrow \mu\left(X_{i}\right)$, then the trust subordination degree of international trade goods exchange rate transaction of qualitative concept $T$ is $X_{i}$; trust cloud drop is the element $X_{i}$ of each risk trust evaluation attribute in the international trade trading platform, where $i=1,2, \ldots, m$.

The trust attribute $X$ of international trade transaction satisfies the following formula for the qualitative concept $T$ :

$$
\mu(X)=e^{-\left(X-E_{X}\right)^{2} / 2 E_{n}^{2}} .
$$

In formula (18), $E_{n}$ and $E_{X}$ represent entropy and expectation, respectively, and the trust cloud $\mu(X)$ of international trade goods exchange rate transaction risk assessment is a one-dimensional normal trust cloud. Let $X_{i j}$ represent the attribute value of the exchange rate transaction risk assessment period of international trade goods, which is called the time attenuation factor, $j$ represent the assessment period, $t_{i j}$ be the timeliness weight of $X_{i j}$, and $t_{i j}$ and $X_{i j}$ meet the following formula:

$$
\frac{t_{i(j-1)}}{t_{i j}}=\frac{t_{i j}}{t_{i(j+1)}} .
$$

In formula (19), $2 \leq j \leq T-1$; the farther away from the time of trust assessment of exchange rate transaction risk of international trade goods, the lower the correctness of the response to the current e-commerce trust level.

Enter the trust cloud $T C_{1}\left(E_{x_{1}}, E_{n 1}, H_{e 1}\right)$ and $T C_{2}\left(E_{x_{2}}, E_{n 2}, H_{e 2}\right)$ for international trade goods exchange rate transaction evaluation, where $H_{e}$ represents hyperentropy. The feature groups of three numbers in $T C_{1}$ and $T C_{2}$ are divided into vectors $\overrightarrow{T C_{1}}$ and $\overrightarrow{T C_{2}}$. The cosine angle between $\overrightarrow{T C_{1}}$ and

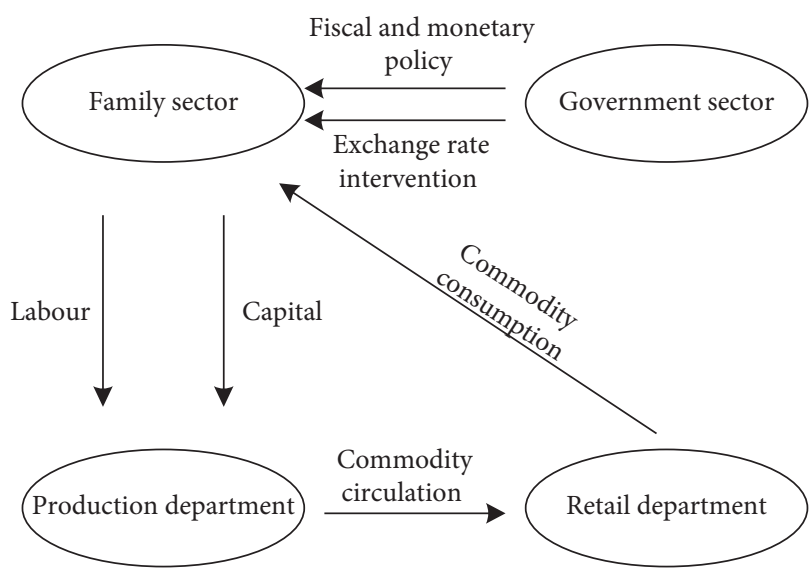

FIgURE 6: Overall framework flow of the dynamic stochastic equilibrium model.

$\overrightarrow{T C_{2}}$ is the similarity between $T C_{1}$ and $T C_{2}$ in the trust cloud of international trade goods exchange rate transaction risk assessment, and its calculation formula is

$$
\begin{aligned}
\operatorname{sim}\left(T C_{1}, T C_{2}\right) & =\cos \left(\overrightarrow{T C_{1}}, \overrightarrow{T C_{2}}\right) \\
& =\overrightarrow{T C_{1}} \times \overrightarrow{T C_{2}} /\left\|\overrightarrow{T C_{1}}\right\| \times\left\|\overrightarrow{T C_{2}}\right\| .
\end{aligned}
$$

The higher the similarity between $T C_{1}$ and $T C_{2}$, the more similar the trust level between $T C_{1}$ and $T C_{2}$.

Each attribute of international trade is divided into $n$ evaluation levels through the trust index of international trade goods exchange rate transaction. $\left[R_{i}^{\min }, R_{i}^{\max }\right)$ represents the partition of the $i$ level. The calculation formula of the evaluation value of this interval is

$$
\text { value }=R_{i}^{\min }+\left(R_{i}^{\max }-R_{i}^{\min }\right) \beta .
$$

In formula (21), $\beta$ represents the weighted percentage of exchange rate transactions of goods in international trade:

$$
X=\left\{x_{1}, x_{2}, \ldots, x_{k}\right\} .
$$

Formula (22) is the comment set; $X_{h}$ is the specific comment, where $h=1,2, \ldots, k$ :

$$
P(X)=\left\{x_{1}, x_{2}, \ldots, x_{k}\right\} .
$$

Formula (23) is the degree of harm caused by international trade goods exchange rate transaction risk events given in the comment set. $P\left(X_{h}\right), h=1,2, \ldots n$ represents the mean value of abnormal transaction risk harm degree of comment $X_{h}$, where $0 \leq P\left(X_{h}\right) \leq 1$.

The formula for calculating the risk value of international trade goods exchange rate transaction is as follows:

$$
R=\sum_{h=1}^{k} P\left(X_{h}\right) \gamma
$$

In formula (24), $X_{h}\left(\gamma_{a}\right)$ represents the credibility of the evaluation factor $\gamma_{a}$ to $X_{h}$, and $\gamma$ represents the risk credibility of the exchange rate transaction of goods in international trade. In summary, it is the principle of risk 
TABLE 2: Values of model variables.

\begin{tabular}{lcc}
\hline Variable & Symbol & Value \\
\hline Consumption & $C$ & Average annual consumer price index \\
Asset price & $p$ & Annual retail price index \\
Interest rate level & $r$ & Central bank benchmark interest rate \\
Labor supply & $l$ & Annual average employment rate \\
Currency balance & $M$ & Annual balance of money supply \\
Asset holdings & $C_{a}$ & Shanghai stock index at the end of the year \\
Exchange rate expectation & $e$ & The current monetary value and foreign exchange reserve value are calculated comprehensively \\
\hline
\end{tabular}

assessment of exchange rate transactions of international trade goods. According to this principle, the study of exchange rate transactions of international trade goods based on fuzzy granulation and deep learning is completed.

\section{Experimental Analysis}

The dynamic stochastic equilibrium model is one of the effective tools to study macroeconomic problems. Based on the new Keynesian theory, the model divides the socioeconomic departments into household departments, government departments, and production departments and analyzes the correlation between the exchange rate changes of international trade goods and the asset prices from three different perspectives. The overall framework of the dynamic stochastic equilibrium model is shown in Figure 6.

Currency provides a medium for the smooth operation of the economy. From the level of the RMB utility function model, a dynamic stochastic model is established based on the three perspectives of the household sector, the government sector, and the production sector.

To better study the relationship between asset prices and exchange rate changes and the steady growth of China's macroeconomy, it is necessary to dig out the main changes in the stock market, real estate market, financial market, and other related fields. Therefore, stock index represents the stock market, real estate price represents the real estate market, and domestic consumer goods index represents the financial market. At the same time, the dynamic stochastic equilibrium model is used to analyze the relationship between asset price and exchange rate by empirical analysis and quantitative research, and the influence process of the two on the steady growth of national economy is obtained.

The dynamic stochastic equilibrium model includes model variables such as expected exchange rate, consumption, price, interest rate, total asset holdings, labor, and real currency balance. The source, interpretation, and significance of each variable in the model are shown in Table 2:

The panel data used in the empirical study comes from the SSE's Shanghai Stock Exchange Index from 2010 to 2020, and relevant statistics of exchange rate changes. This paper studies the correlation between asset prices and exchange rate changes from the perspective of exchange rate changes and expectations, impact on the Shanghai Composite Index, and price transmission path. Trends in exchange rate changes, exchange rate expectations, and the Shenzhen Stock Exchange Index over the past decade are shown in Figure 7.

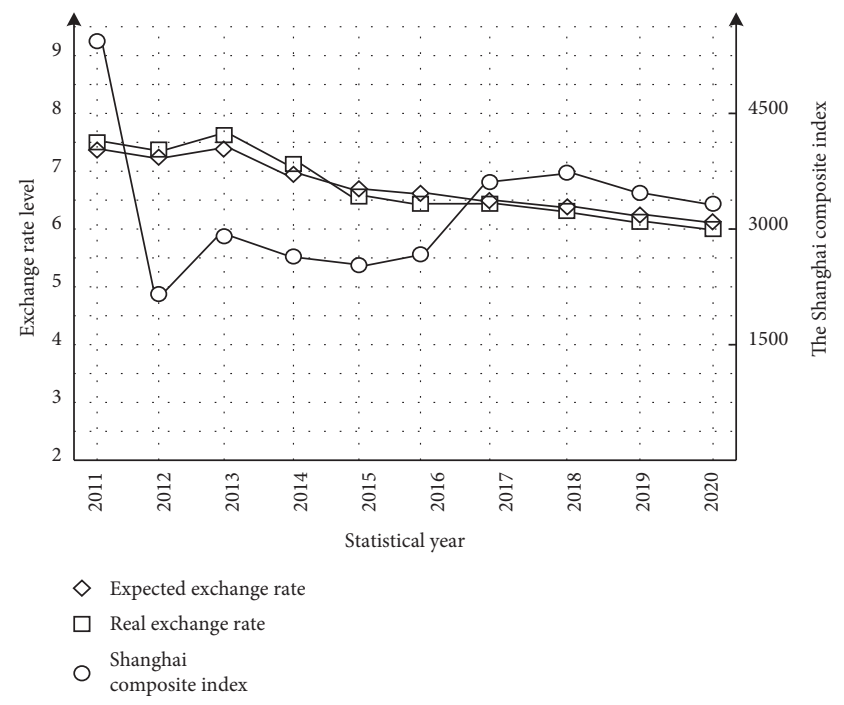

FIGURE 7: Overall trend of exchange rate change and asset price change.

It can be seen from Figure 7 that the expected change of RMB exchange rate from 2011 to 2020 is consistent with the actual change area, which indicates that the national macrocontrol policies and monetary policies have played a positive role in ensuring the stability of China's RMB base exchange rate and promoting the development of the country's macroeconomy. However, from the analysis of the overall trend of exchange rate changes in the past ten years, a slow downward trend is still shown, that is, from 7.5 in 2010 to 6.1 in 2020 (the exchange rate between RMB and US dollar). In 2008, the global financial crisis broke out, which also led to the turbulence of China's stock market. The Shanghai Stock Market also suffered a cliff fall, and asset prices declined significantly. At this level, changes in asset prices led to the country's economic decline. Therefore, under the coordination of RMB and asset prices, the country's economy can maintain steady growth.

\section{Conclusion}

With the increasing trend of global financial and economic integration, the economic development model is converging with the international trend, while exchange rate fluctuations and financial risks from the international environment affect the stability of economic growth. From the two levels of fuzzy granulation and BP neural network in deep learning, the research on exchange rate transaction of international 
trade goods is discussed respectively, and the conclusions are as follows. From the analysis of the overall trend of exchange rate changes in the past decade, a slow downward trend is still shown. Excessive exchange rate fluctuations will bring about the same proportion fluctuations to asset prices in the financial market, which will bring serious harm to economic development and is not conducive to the stability of regional and world economy and the improvement of the international trade system.

The next research work can consider shortening the time interval to make the data sampling points used in the experiment denser on the time axis, to get closer to the real market and make the exchange rate fluctuations develop in a healthy and orderly way.

\section{Data Availability}

The raw data supporting the conclusions of this article will be made available by the corresponding author.

\section{Conflicts of Interest}

The authors declare that they have no conflicts of interest regarding this work.

\section{References}

[1] N. N. Diner, A. Shingal, and A. Tekin-Koru, "Trade and exchange rate effects: evidence from firm-level data," Working Papers, vol. 20, no. 10, pp. 1403-1410, 2020.

[2] C. Tunc, S. Babuu, A. Hazar, and M. N. Solakoglu, "Exchange rate volatility and trade: external exchange rate volatility matters," Journal of International Commerce Economics and Policy, vol. 11, no. 2, Article ID 2050006, 2020.

[3] K. Guei and I. Choga, "Exchange rate volatility and regional trade agreements in Southern Africa," Economic Change and Restructuring, vol. 10, no. 3, pp. 23-30, 2021.

[4] B. Gaa and C. Hc, "The dynamics of the U.S. trade balance and real exchange rate: the J curve and trade costs," Journal of International Economics, vol. 132, no. 4, Article ID 103511, 2021.

[5] Z. Chen, J. Hong, and X. Sun, "Exchange rate risk and trade mode choice in processing trade: evidence from Chinese data," Review of International Economics, vol. 28, no. 2, pp. 537-564, 2020.

[6] B. Zhang, S. Bai, Y. Ning, T. Ding, and Y. Zhang, "Emission embodied in international trade and its responsibility from the perspective of global value chain: progress, trends, and challenges," Sustainability, vol. 12, no. 8, pp. 1-26, 2020.

[7] S. Ali, "Exchange rate effects on agricultural exports: transaction-level evidence from Pakistan," American Journal of Agricultural Economics, vol. 102, no. 3, pp. 1020-1044, 2020.

[8] A. J. Nagengast, D. Bursian, and J.-O. Menz, "Dynamic pricing and exchange rate pass-through: evidence from transaction-level data," European Economic Review, vol. 133, no. 1, Article ID 103662, 2021.

[9] S. Hohberger, M. Ratto, and L. Vogel, "The euro exchange rate and Germany's trade surplus," International Finance, vol. 23, no. 4, pp. 85-103, 2020.

[10] T. T. Nguyen, T. L. D. Huynh, and W. K. Wong, "Factors driving openness in China trade: corruption, exchange rate volatility, and macro determinants," Review of Pacific Basin
Financial Markets and Policies, vol. 24, no. 2, Article ID 2150016, 2021.

[11] S. Auray, M. B. Devereux, and A. Eyquem, "Endogenous trade protection and exchange rate adjustment," NBER Working Papers, vol. 12, no. 6, pp. 1-43, 2019.

[12] W. J. Ethier and A. L. Hillman, "The politics of international trade," CESifo Working Paper Series, vol. 2, no. 4, pp. 653-683, 2019.

[13] Y. Han, F. Zhang, and D. Cao, "Research on Guangzhou's construction into an international trade center of the Guangdong-Hongkong-Macao greater bay area: a city competitiveness perspective," Urban Insight, no. 1, pp. 75-92, 2020.

[14] R. Cezar and T. Polge, "CO2 emissions in French international trade[Les émissions de $\mathrm{CO} 2$ dans les échanges internationaux de la France]," Bulletin de la Banque de France, vol. 229, no. 4, pp. 15-23, 2020.

[15] S. Gül and R. Gupta, "Time(arying impact of global, region and country:pecific uncertainties on the volatility of international trade," Contemporary Economic Policy, vol. 39, no. 4, pp. 691-700, 2021.

[16] R. J. Patel, "International trade and stock market integration," Evidence from study of India and its major trading partners, vol. 18, no. 2, pp. 45-53, 2020.

[17] E. Bontempi and M. Coccia, "International trade as critical parameter of COVID-19 spread that outclasses demographic, economic, environmental, and pollution factors," Environmental Research, vol. 201, no. 1, Article ID 111514, 2021.

[18] H. H. Nguyen, "Impact of foreign direct investment and international trade on economic growth: empirical study in vietnam," The Journal of Asian Finance, Economics and Business, vol. 7, no. 3, pp. 323-331, 2020.

[19] Y. A. Khan and M. Ahmad, "Investigating the impact of renewable energy, international trade, tourism, and foreign direct investment on carbon emission in developing as well as developed countries," Environmental Science and Pollution Research, vol. 28, no. 24, pp. 1-10, 2021.

[20] S. Muhammad, X. Long, M. Salman, and L. Dauda, "Effect of urbanization and international trade on $\mathrm{CO} 2$ emissions across 65 belt and road initiative countries," Energy, vol. 196, no. 1, Article ID 117102, 2020.

[21] Z. Wang, D. Nong, A. M. Countryman, J. J. Corbett, and T. Warziniack, "Potential impacts of ballast water regulations on international trade, shipping patterns, and the global economy: an integrated transportation and economic modeling assessment," Papers, vol. 26, no. 8, pp. 98-105, 2020.

[22] R. Schumacher, "Altering the pattern of trade in the wealth of nations: adam smith and the historiography of international trade theory," Journal of the History of Economic Thought, vol. 42, no. 1, pp. 19-42, 2020.

[23] D. Blandford, "Robert W.fraser, david C.cook and JanetHaddock-fraser. 2021. The WTO and environment-related international trade disputes, biosecurity and ecosystem services risks. UK: world scientific publishing europe ltd., ISBN: 97817863447770. Publisher's prices: $£ 85, \$ 98$," Journal of Agricultural Economics, vol. 72, no. 1, pp. 329-330, 2021.

[24] T. Wyatt, "Canada and the convention on international trade in endangered species of wild fauna and flora (CITES): lessons learned on implementation and compliance," Liverpool Law Review, vol. 42, no. 2, pp. 143-159, 2021.

[25] A. Khaskheli, Y. Jiang, S. A. Raza, and K. A. Khan, "Financial development, international trade, and environmental degradation: a nonlinear threshold model based on panel smooth transition regression," Environmental Science and Pollution Research, vol. 28, no. 1, pp. 26449-26460, 2021. 
[26] D. Czyewski, "The relationship between the international trade and economic growth accounting for model uncertainty and reverse causality," Mpra Paper, vol. 14, no. 14, Article ID 108405, 2021.

[27] P. Barkas, D. Honeck, and E. Rubio, "International trade in travel and tourism services: economic impact and policy responses during the COVID-19 crisis," WTO Staff Working Papers, 2020.

[28] Danish, "Moving toward sustainable development: the relationship between water productivity, natural resource rent, international trade, and carbon dioxide emissions," Sustainable Development, vol. 28, no. 4, pp. 540-549, 2020.

[29] J. P. Daniels, E. Kapszukiewicz, and M. Ruhr, "International trade policy preferences: the impact of patriotism and nationalism pre- and post-9/11," Atlantic Economic Journal, vol. 48, no. 209, pp. 87-98, 2020.

[30] R. V. Kalafsky and D. R. Gress, "Minimizing distance: international trade fairs and SME targeting of specific export markets," Geojournal, vol. 85, no. 3, pp. 1025-1037, 2020.

[31] R. G. Volkov, "The main approaches to assessing the impact of non-tariff measures on international trade," International Trade and Trade Policy, vol. 391, no. 2, pp. 45-53, 2020.

[32] J. Wolszczakderlacz, "The impact of China one-belt one-road initiative on international trade and global value chains," Gut Fme Working Paper Series A, vol. 62, no. 12, pp. 59-63, 2020.

[33] S. Jaki, N. Erjavec, and B. Cota, "Impact of regulatory trade barriers and controls of the movement of capital and people on international trade of selected Central, Eastern and Southeastern European economies," Central European Journal of Operations Research, vol. 29, no. 4, pp. 891-907, 2021.

[34] F. Torti, M. Riani, and G. Morelli, "Semiautomatic robust regression clustering of international trade data," Statistical Methods and Applications, vol. 30, no. 3, pp. 863-894, 2021.

[35] X. Chuai, Q. Lu, X. Huang, and R. Gao, "China's construction industry-linked economy-resources-environment flow in international trade," Journal of Cleaner Production, vol. 1, no. 1, Article ID 123990, 2020. 